\title{
Moderate hypothermia and its effects in reducing the applied dose of anesthetics for patients with opium dependence in cardiac surgery: A randomized controlled trial
}

\author{
Reza Jalaian Taghadomi ${ }^{1}$, Ebrahim Golmakani ${ }^{2}$, Kambiz Alizadeh ${ }^{3}$, Behrooz Mottahedi ${ }^{4}$, Ali Rahdari ${ }^{5}$, Shima
} Sheybani ${ }^{6}$

\footnotetext{
${ }^{1}$ M.D., Associate Professor, Department of Anaesthesiology, Faculty of Medicine, Mashhad University of Medical Sciences, Iran

${ }^{2}$ M.D., Assistant Professor, Department of Anaesthesiology, Faculty of Medicine, Mashhad University of Medical Sciences, Iran

${ }^{3}$ M.D., Assistant Professor, Department of Cardiac Surgery, Faculty of Medicine, Mashhad University of Medical Sciences, Iran

${ }^{4}$ M.D., Associate Professor, Department of Cardiac Surgery, Faculty of Medicine, Mashhad University of Medical Sciences, Iran

${ }^{5}$ M.D., Anesthesiologist, Department of Anaesthesiology, Faculty of Medicine, Mashhad University of Medical Sciences, Iran

${ }^{6}$ M.D., Fellowship of Anesthesia in Cardiac Surgery, Assistant Professor, Faculty of Medicine, Mashhad University of Medical Sciences, Mashhad, Iran
}

Type of article: Original

\begin{abstract}
Background: An increasing number of patients addicted to opium are experiencing awareness during coronary artery bypass surgery (CABG) as a result of tolerance to anesthetics.

Objectives: This research was primarily intended to determine the potential diminishing effects of moderate hypothermia on anesthetic dosage and recall of anesthesia during the procedure.

Methods: In this double-blind randomized controlled trial, a total of 80 CABG candidates with known addiction to opium were divided into two groups: one normothermic $(\mathrm{N})$ and the other moderately hypothermic $(\mathrm{H})$, both undergoing induction as well as close monitoring from September 2014 to January 2016. The candidates were initially set for a target bispectral index (BIS) score of between 40 and 60. As the score rose to 60, an additional dose of propofol was administered, alongside rise in blood pressure and tear-shedding. To enhance the accuracy of our evaluation of anesthetic depth, we also used two questionnaires to test candidates' recall filled with the assistance of a colleague 24 hours following surgery. Independent-samples t-test and chi-square test were used by SPSS v 18 for data analysis.

Results: Eighty patients were studied in two groups of normothermic $(N)(n=40)$ and hypothermic $(H)(n=40)$. Given similar demographic data as well as the duration of surgery, we arrived at a propofol dose of $122.52 \pm 13.11$ $\mathrm{cc}$ for normothermic patients and $101.28 \pm 14.06 \mathrm{cc}$ for hypothermic subjects $(\mathrm{p}=0.001)$. As for fentanyl, the total required sum came up to $39.60 \pm 21.04 \mathrm{cc}$ and $31.72 \pm 5.81 \mathrm{cc}$ for the above-mentioned groups in order $(\mathrm{p}=0.025)$. Moreover, the post-operative interview showed that there was no report of a patient with memory recall following surgery.

Conclusions: Moderate hypothermia can substantially reduce the need for anesthetics in patients with addiction to opium when undergoing CABG surgery.

Trial registration: This study is registered in Iranian Registry of Clinical Trials with registration number of IRCT2014050513159N5.

Funding: This research was supported financially by the Research Council of Mashhad University of Medical Sciences (grant number 920405).

Keywords: Moderate hypothermia; Normothermia; Anesthetic depth; Opium addiction, Coronary artery bypass
\end{abstract}

\section{Corresponding author:}

Assistant Professor Dr. Shima Sheybani, Department of Anesthesiology, Ghaem Hospital, Mashhad University of Medical Sciences, Iran. Tel: +98.9151140314, Email: Sheybanish@mums.ac.ir

Received: February 01, 2016, Accepted: August 21, 2016, Published: September 2016

iThenticate screening: August 16, 2016, English editing: September 02, 2016, Quality control: September 06, 2016

(C) 2016 The Authors. This is an open access article under the terms of the Creative Commons Attribution-NonCommercialNoDerivs License, which permits use and distribution in any medium, provided the original work is properly cited, the use is non-commercial and no modifications or adaptations are made. 


\section{Introduction}

Substance abuse, particularly with opioids and opium, has long been a health and social challenge the world over, especially in Iran (1-3). There has been a threefold rise in rates pertaining to narcotics use over the past two decades. Patients undergoing bypass surgery seem to have been misled by the prevailing fallacy that opium use contributes to their overall health and recovery (1). This has led to an overall consumption rate of $9 \%$ to $15.6 \%$ among this category of patients (4-7). Opium use, on the other hand, can partially raise tolerance to anesthetics, with addicts requiring higher doses of drugs during surgery $(8,9)$. One particular operation, which makes it highly likely for patients to experience awareness and consciousness throughout the procedure, is coronary bypass surgery. It is thus recommended that the anesthetist in charge should keep a close eye on BIS scores to prevent this state (10, 11). Bispectral index (BIS) is one of several technologies used to monitor the depth of anesthesia. It is chiefly determined by a number of parameters, namely, body temperature and narcotics use. Every $1{ }^{\circ} \mathrm{C}$ drop can cause a reduction of 1.12 BIS score (12). Nevertheless, severe hypothermia $\left(15-28^{\circ} \mathrm{C}\right)$ has been proven to play havoc with this index, thus moderate hypothermia $\left(28-34{ }^{\circ} \mathrm{C}\right)$ is preferred in this state (13). It also has been shown to be prior to mild hypothermia $\left(34-36^{\circ} \mathrm{C}\right)$, which raises the doses of anesthetics. BIS indices are also shown to be more accurate when anesthesia is combined with mild to moderate analgesia. In this case, if BIS is applied along with large opioid doses, the use of a hypnotic may be required as well to prevent awareness (14). Infusions of fentanyl, alfentanil, remifentanil, and sufentanil can induce anesthesia at lower doses of propofol, whereas BIS indices appear higher as opioids can exert slight eletrophysiologic alterations on the cortex undetected by EEG $(15,16)$. All this is indicative of the fact that propofol anesthetic effects are augmented in cases of opioid use, which remain undetected by BIS. Thus, it is incumbent on the part of the anesthetist to practice care and caution to avoid propofol overdose besides BIS monitoring during general anesthesia (17). Opium addicts also are prone to present with awareness and consciousness during surgery (18). Given the growingly high prevalence of opium use among patients undergoing $\mathrm{CABG}$ and the fact that the already affected required dose of anesthetic drugs also are at the mercy of body temperature, we intended to determine the effect of moderate hypothermia on the depth of anesthesia in patients with opium addiction undergoing $\mathrm{CABG}$.

\section{Material and Methods}

\subsection{Research design and setting}

This double-blind random clinical trial was conducted on opium-addicted patients having to undergo first-time coronary artery bypass grafting (CABG) surgery in Qaem Hospital, Cardiovascular Surgery Mashhad, Iran, during September 2014 to January 2016.

\subsection{Participants}

Patients were included if their opium use and addiction were confirmed based on DSM-IV criteria (19). In accordance with DSM-IV criteria, an individual was categorized as a dependent when recurring difficulties arose throughout a 1-year period in pertinent areas, namely, functioning, using greater amounts of opiates than intended, besides continuing to use them despite the negative consequences (20). All patients reported constant habitual use of opium over a 1-year period. Abusers were not contained in this study. The following patients were excluded: 1) those who had undergone CABG and general anesthesia; 2) those with the history of non-opiate substance use, alcohol; and sedatives; 3 ) those with a psychotic condition; 4) those classified above ASA (the American Society of Anesthesiologists) class III.

\subsection{Sample size}

We estimated a sample size of 35 in each group using an $\alpha$ value of 0.05 with a power of $90 \%$ and possible $20 \%$ follow-up loss via sample size formula based on comparing two means. $N=\left(\mathrm{Z}_{1-\alpha / 2}+\mathrm{Z}_{1-\beta / 2}\right)^{2} \mathrm{x} 621+622 / \mathrm{d}^{2}=35$ per each group.

\subsection{Randomization and blinding}

Computer-generated randomization was conducted by a university statistician. These patients, male and female, all aged between 30-75 class II and III based on ASA and were subsequently divided into two 40-member groups to which they were blind using codes. The patient was not aware of the type of intervention being used.

\subsection{Interventions}

The selected patients were given opium at the regular dose as before throughout the pre-operative phase. An arterial blood sample also was taken as surgery commenced. Pre-operative medications were continued until the day of surgery, with the exception of angiotensin-converting-enzyme inhibitors. Anesthesia was induced by injecting an 
intravenous cocktail of titrated midazolam (5 mg), fentanyl (7-10 $\left.\mu \mathrm{g} \cdot \mathrm{kg}^{-1}\right)$, propofol $\left(1 \mathrm{mg} \cdot \mathrm{kg}^{-1}\right)$, and atracurium $(0.6$ mg. $\mathrm{kg}^{-1}$ ) following the placement of BIS (Covidien Boulder, CO, USA). Afterward, it was maintained with propofol (50 mg.kg $\left.{ }^{-1} \cdot \mathrm{min}^{-1}\right)$, fentanyl $\left(1-2 \mu \mathrm{g} \cdot \mathrm{kg}^{-1} \cdot \mathrm{hr}^{-1}\right)$, and atrecurium $\left(0.01 \mathrm{mg} \cdot \mathrm{kg}^{-1} \cdot \mathrm{min}^{-1}\right)$. Routine monitoring included two-channel electrocardiogram (II and V5), radial artery pressure, pulse oximetry, central venous pressure, esophageal temperature, and capnography and BIS. Group H underwent CABG under moderate hypothermia (28-34 ${ }^{\circ} \mathrm{C}$ ) as opposed to group $\mathrm{N}$, which experienced normothermia, both by pump and their hearts beating during the procedure (Figure 1). If body temperature fell below $36^{\circ} \mathrm{C}$ in the normothermic group, the rewarming occurred. In the case of temperatures greater than $38^{\circ} \mathrm{C}$, cooling blankets were applied. More to the point, both groups were comparable in terms of the intraoperative anesthetic procedure, and the postoperative sedation, analgesia, and intensive care unit (ICU) discharge protocols. Patients were all intubated with an esophageal tube, and an esophageal thermometer was placed for further monitoring. A CV line also was placed on the right inter-jugular vein. The above-mentioned cocktail was administered, with the anesthetist recording the depth of anesthesia all throughout the procedure. A BIS score of 40-60 was maintained in every stage in both normothermic and hypothermic groups. In the latter category, body temperature was gradually reduced to $30{ }^{\circ} \mathrm{C}$ following aortic cannulation and beginning of cardiopulmonary bypass (CPB) by cooling blankets. In case BIS exceeded 60, an additional dose of opioid (fentanyl 50-100 $\mu \mathrm{g}$ ) and propofol $(20 \%$ in excess of the maintenance dose) was administered. Muscle relaxants also were used. Patients were monitored for blood pressure rise and tear-shedding. The target mean arterial pressure (MAP) was $70-90 \mathrm{~mm} \mathrm{Hg}$ and 50-60 $\mathrm{mmHg}$ prior to and during artificial pumping, respectively. In case of drastic alteration of MAP exceeding $20 \mathrm{~mm} \mathrm{Hg}$, vasodilators and vasopressors were applied.



Figure 1. Follow-up diagram of patients (according to consort statement)

\subsection{Outcomes}

We recorded all the pertinent amounts throughout the operation and extubation time in both groups. In order to evaluate the depth of anesthesia, we also applied two questionnaires used in former research, besides the checklist, 
to be filled by anesthetist $(9,18,21,22)$. They are intended for enhancing the accuracy of the data obtained; in doing so, we preferred a colleague, who was neither aware of our study nor was involved with the anesthetic procedures during the operation, to help with open-ended questions 24 hours following extubation when patients are less likely to be uncooperative. Questions were read out to patients in order. Subjects were initially asked if they remember the last thing before, the first thing after surgery, or anything in between and whether they were dreaming during surgery. A negative answer to these questions meant the termination of the interview, an indication of lack of awareness or consciousness during the intervention, whereas a positive answer ensued enquiries pertaining to the details of the experience in the subjects' own words, their perceptive patterns, audio-visual, tactile, sensory experiences such as pain and paralysis, state of panic, frustration, fright, weakness, vulnerability and so forth, and whether they made any attempt, no matter how feeble, to draw others' attention to their condition. All replies were duly noted and recorded.

\subsection{Research ethics}

The study was approved and authorized by the Committee of Medical Ethics, Mashhad University of Medical Sciences (Code: 920405). All patients gave their consent in writing following being enlightened on the objectives and method of the study, and they were free to participate or withdraw. We performed all our procedures under supervision of a scientific committee who were experts in the field of cardiac surgery and anesthesiology; thus we were responsible for any consequences of the patient's procedures; further, no harmful consequences were observed.

\subsection{Statistical methods}

In analysis, we conducted both descriptive and analytical processes, applying SPSS v.18 (SPSS Inc., Chicago, IL, USA), independent-samples t-test, and chi-square test. A $p$-value of 0.05 was considered highly significant. Given the normal distribution of our data, we decided to use parametric tests.

\section{Results}

\subsection{Baseline characteristics}

Eighty patients were studied in two groups of normothermic $(N)(n=40)$ and hypothermic $(H)(n=40)$. The average age was $56.36 \pm 8.41$ years (minimum 42 and maximum 70 ). Demographic information regarding the study groups is presented in Table I. Both groups were homogenous in terms of age $(p=0.284)$, gender $(p=0.745)$, weight $(p=0.868)$, and surgery duration $(\mathrm{p}=0.072)$ (Table 1$)$.

Table 1. Baseline characteristics of the study's participants

\begin{tabular}{|l|l|l|l|l|}
\hline Baseline Variables & $\begin{array}{l}\text { Normothermic } \\
\text { Group }(n=40)\end{array}$ & $\begin{array}{l}\text { Hypothermic } \\
\text { Group }(n=40)\end{array}$ & $\begin{array}{l}\text { Total } \\
(n=80)\end{array}$ & $p$-value \\
\hline Age, year (mean \pm SD) & $55.35 \pm 8.57$ & $57.38 \pm 8.22$ & $56.36 \pm 8.41$ & 0.284 \\
\hline Gender (male:female) & $34: 6$ & $35: 5$ & $69: 11$ & 0.745 \\
\hline Weight, Kg (mean \pm SD) & $73.18 \pm 14.25$ & $73.70 \pm 13.87$ & $73.44 \pm 13.98$ & 0.868 \\
\hline Duration of surgery, minute $($ mean \pm SD) & $200.00 \pm 17.32$ & $166.43 \pm 28.45$ & $173.68 \pm 26.92$ & 0.072 \\
\hline
\end{tabular}

\subsection{Outcomes}

The average dose of 1\% propofol used in all two groups was measured $106.76 \pm 14.59 \mathrm{cc}$ (group H: $101.28 \pm 14.06 \mathrm{cc}$ and group N: $122.52 \pm 13.11 \mathrm{cc})(\mathrm{p}=0.001)$, whereas that of fentanyl was reported to be $35.66 \pm 15.85 \mathrm{cc}$ in quantity (group H: $31.72 \pm 5.81 \mathrm{cc}$ and group $\mathrm{N} 39.60 \pm 21.04 \mathrm{cc})(\mathrm{p}=0.025)$. There was a significant difference in the need for anesthetic drugs between both groups (Table 2). Besides, the result of the post-operative interview revealed that there was no report of a patient with memory of the surgery.

Table 2. Primary outcome between study groups

\begin{tabular}{|l|l|l|l|l|}
\hline Used anesthetic drugs & $\begin{array}{l}\text { Normothermic } \\
\text { Group }(n=40)\end{array}$ & $\begin{array}{l}\text { Hypothermic } \\
\text { Group }(n=40)\end{array}$ & $\begin{array}{l}\text { Total } \\
(n=80)\end{array}$ & $p$-value \\
\hline Propofol, cc (mean \pm SD) & $122.52 \pm 13.11$ & $101.28 \pm 14.06$ & $106.76 \pm 14.59$ & 0.001 \\
\hline Fentanyl, cc (mean \pm SD) & $39.60 \pm 21.04$ & $31.72 \pm 5.81$ & $35.66 \pm 15.85$ & 0.025 \\
\hline
\end{tabular}

\section{Discussion}

Hypothermia has long been hailed as an adjunct protective measure in cardiac surgery anesthesia, with known multisystem benefits. Research has shown that adults seem to be susceptible for intraoperative awareness during 
general anesthesia, namely, throughout cesarean delivery, cardiopulmonary bypass, and surgery for major trauma (23). Furthermore, it was reported that higher ASA physical status, neuromuscular blocking drugs, small doses of the primary anesthetic, and opium addiction have augmented the incidence rate of awareness (23-25). Of note, opium addiction in patients undergoing $\mathrm{CABG}$ also has been associated with excessive postoperative bleeding, longterm healthcare resource utilization as well as re-hospitalization $(23,26,27)$. A considerable number of scholars have regarded hypothermia as a means of reducing the need for anesthetic drugs during such operations. Kim and Joo investigated the effects of mild intraoperative hypothermia and core normothermia on anesthetic drugs (namely, propofol and isoflurane) pharmacology and recovery profile to set BIS 40-60 in patients undergoing endoscopic sinus surgery. The authors reported that more drug requirements had been observed in propofol anesthesia in subjects who underwent mild hypothermia. Nevertheless, the recovery time was similar in all four groups (28). Our findings revealed that, in order to achieve a BIS score of between 40 to 60, higher doses of both propofol and fentanyl were needed in group $\mathrm{N}$ (normothermics) than group $\mathrm{H}$ (hypothermics). None of the patients in either group $\mathrm{H}$ or $\mathrm{N}$ could recall anything pertaining to the surgery (negative answer to the first three questions). In a study conducted by Honan et al., there had been a random comparison between 30 patients experiencing mild (14 subjects) and moderate (16 subjects) hypothermia during their bypass surgery, with the former having presented with lower BIS indices (28). Another study by Dewandre et al. showed consistency in BIS scales following a drastic drop during induction in 10 moderately hypothermic patients having undergone CABG irrespective of surgical stimuli (30). That was in contrast with Honan's and ours, indicating the need for drug adjustment when hypothermia is induced. Chandran et al. investigated the minimum required dose of sevoflurane so as to maintain a target BIS of 4050 during $\mathrm{CABG}$ under moderate hypothermic conditions. The need for sevoflurane increased drastically and predictably as rewarming was taking place so that BIS could be maintained at the desired level (31). This was consistent with our findings regarding the greater needed dose of fentanyl and propofol. Schmidlin et al. analyzed EEGs taken from hypothermic $(\mathrm{n}=14)$ and normothermic $(\mathrm{n}=14)$ patients undergoing CABG so as to monitor their sedation level. Mean BIS was shown to be significantly less in subjects experiencing hypothermia in comparison with normothermic counterparts (41 as opposed to 49). There are still controversies as to whether this can be attributed to brain cooling or owing pharmacodynamic alterations, which can raise propofol concentration (32). Mathew et al. also corroborated that brain function and, thus, the need for anesthetic decline when cooling takes place. In their research, a total of 100 patients were monitored under hypothermia, with the final analysis reporting a 1.12 score reduction in BIS for every $1^{\circ} \mathrm{C}$ drop in temperature (12). The authors conducted another study in 2009 , which aimed at determining the required dose of propofol in hypothermic $\left(28-30^{\circ} \mathrm{C}\right)$ and normothermic patients $(35-$ $37^{\circ} \mathrm{C}$ ) having undergone elective CABG. Their target BIS score was $50 \pm 10$ (33). Their findings were akin to ours, indicating that hypothermia decreased the need for propofol without any adverse impact on the depth anesthesia, as no subject had any recall of surgery. The study was different from ours in that we determined addicts and applied fentanyl as well.

\section{Limitations}

As for the limitation of the study, several studies have doubted the effectiveness of BIS monitoring during CPB. Puri and Murthy reported BIS guidance to be of utmost assistance for reducing hemodynamic instability rates and for enhancing anesthetic agents' titration. Nevertheless, there have been great disparities in BIS values in patients under CPB $(34,35)$. Schmidlin et al. also detected large BIS variations, which often were within the range of awake indices during normothermic CPB. Similarly, the effectiveness of BIS monitoring was reported to be questioned during cardiac surgery in infants (32). Despite this limitation, our work laid the ground for further investigation on the effects of opium addiction on anesthetics for patients undergoing cardiac surgery.

\section{Conclusions}

The findings revealed that hypothermia can significantly reduce the need for propofol and fentanyl to achieve a desirable BIS during CABG in patients addicted to opium who otherwise require greater doses of anesthetics. There also were no reports on post-operative recall of the patients.

\section{Acknowledgments:}

The findings revealed that hypothermia can significantly reduce the need for propofol and fentanyl to achieve a desirable BIS during CABG in patients addicted to opium who otherwise require greater doses of anesthetics. There also were no reports on post-operative recall of the patients.

\section{Trial registration:}

This study is registered in the Iranian Registry of Clinical Trials with registration number IRCT2014050513159N5. 


\section{Funding:}

This research was supported financially by the Research Council of Mashhad University of Medical Sciences (Grant number: 920405). The authors received no financial support for the authorship and/or publication of this article.

\section{Conflict of Interest:}

There is no conflict of interest to be declared.

Authors' contributions:

All authors contributed to this project and article equally. All authors read and approved the final manuscript.

\section{References:}

1) Abdollahi $\mathrm{MH}$, Forouzan SKH, Zahreh S. Demografic characteristics of opioid addiction in patients undergoing Coronary Artery Bypass Graft. Tehran University Med J. 2006; 64(10): 54-9.

2) Paul L, Schiff Jr. Opium and its alkaloids. Am J Pharm Educ. 2002; 66(2): 188-96.

3) Safaii N, Kazemi B. Effect of opium use on short-term outcome in patients undergoing coronary artery bypass surgery. Gen Thorac Cardiovasc Surg. 2010; 58(2): 62-7. doi: 10.1007/s11748-009-0529-7. PMID: 20155341.

4) Azarasa M, Azarfarin R, Changizi A, Alizadehasl A. Substance use among Iranian cardiac surgery patients and its effects on short-term outcome. Anaesth Analg. 2009; 109(5): 1553-9. doi: 10.1213/ANE.0b013e3181b76371. PMID: 19843794.

5) Nemati MH, Astaneh B, Ardekani GS. Effects of opium addiction on bleeding after coronary artery bypass graft surgery: report from Iran. Gen Thorac Cardiovasc Surg. 2010; 58(9): 456-60. doi: 10.1007/s11748010-0613-z. PMID: 20859724.

6) Sabzi F, Zokaei AH, Moloudi AR. Predictors of atrial fibrillation following coronary artery bypass grafting. Clin Med Insights Cardiol. 2011; 5: 67-75. doi: 10.4137/CMC.S7170. PMID: 21836815, PMCID: PMC3153115.

7) Sadeghian S, Karimi A, Dowlatshahi S, Ahmadi SH, Davoodi S, Marzban M, et al. The association of opium dependence and postoperative complications following coronary artery bypass graft surgery: a propensity-matched study. J Opioid Manag. 2009; 5(6): 365-72. PMID: 20073410.

8) Lerchl-Wanie G, Angster R. Perioperative analgesia for opioid tolerant patients. Anaesthesist. 2010; 59(7): 657-70. doi: 10.1007/s00101-010-1757-z. PMID: 20625693.

9) $\mathrm{Xu} \mathrm{L}, \mathrm{WU}$ AS, Yue Y. The incidence of intra operative awareness during general anesthesia in China: a multi-center observational study. Acta Anaesthesiol Scand. 2009; 53(7): 873-82. doi: 10.1111/j.13996576.2009.02016.x. PMID: 19496761.

10) Bauer M, Wilhelm W, Kraemer T, Kreuer S, Brandt A, Adams HA, et al. Impact of bispectral index monitoring on stress response and propofol consumption in patients undergoing coronary artery bypass surgery. Anesthesiology. 2004; 101(5): 1096-104. doi: 10.1097/00000542-200411000-00008. PMID: 15505444.

11) Chiu CL, Ong G, Majid AA. Impact of bispectral index monitoring on propofol administration in patients undergoing cardiopulmonary bypass. Anaesth Intensive Care. 2007; 35(3): 342-7. PMID: 17591126.

12) Mathew JP, Weatherwax KJ, East CJ, White WD, Reves JG. Bispectral analysis during cardiopulmonary bypass: the effect of hypothermia on the hypnotic state. J Clin Anesth. 2001; 13(4): 301-5. doi: 10.1016/S0952-8180(01)00275-6. PMID: 11435056.

13) Meybohm P, Gruenewald M, Höcker J, Renner J, Graesner JT, Ilies C, et al. Correlation and agreement between the bispectral index vs. state entropy during hypothermic cardio-pulmonary bypass. Acta Anaesthesiol Scand. 2010; 54(2): 169-75. doi: 10.1111/j.1399-6576.2009.02138.x. PMID: 19839944.

14) Vassiliadis M, Geros D, Maria K. Awareness despite low spectral entropy values. Anesth Analg. 2007; 105(2): 535. doi: 10.1213/01.ane.0000265663.88180.86.

15) Lysakowski C, Dumont L, Pellegrini M, Clergue F, Tassonyi E. Effects of fentanyl, alfentanil, remifentanil and sufentanil on loss of consciousness and bispectral index during propofol induction of anaesthesia. $\mathrm{Br} \mathrm{J}$ Anaesth. 2001; 86(4): 523-7. doi: 10.1093/bja/86.4.523. PMID: 11573626.

16) Struys MM, Vereecke H, Moerman A, Jensen EW, Verhaeghen D, De Neve N, et al. Ability of the bispectral index, autoregressive modelling with exogenous input-derived auditory evoked potentials, and predicted propofol concentrations to measure patient responsiveness during anesthesia with propofol and remifentanil. Anesthesiology. 2003; 99(4): 802-12. doi: 10.1097/00000542-200310000-00010. PMID: 14508310 . 
17) Duarte LT, Saraiva RÂ. When the bispectral index (bis) can give false results. Rev Bras Anestesiol. 2009; 59(1): 99-109. doi: 10.1590/S0034-70942009000100013. PMID: 19374221.

18) Malek B, Seghlis R, Dabbagh A. Awareness during anesthesia in elective abdominal surgery in opium abusers. Tehran University Med J. 2010; 67(10): 731-5.

19) Sadock BJ, Sadock VA. Kaplan and Sadock's concise textbook of clinical psychiatry. Philadelphia: Lippincott Williams \& Wilkins. 2008.

20) Schuckit MA. Opioid drug abuse and dependence. In: Fauci AS, Braunwald E, Kasper DL, Hauser SL, Longo DL, Jameson JL, Loscalzo J, eds. Harrison's principles of internal medicine. New York: McGraw Hill. 2008.

21) Esaki RK, Mashour GA. Levels of consciousness during regional anesthesia and monitored anesthesia care: patient expectations and experiences. Anesth Analg. 2009; 108(5): 1560-3. doi: 10.1213/ane.0b013e31819c2aa3. PMID: 19372336.

22) Malviya S, Galinkin JL, Bannister CF, Burke C, Zuk J, Popenhagen M, et al. The incidence of intraoperative awareness in children: childhood awareness and recall evaluation. Anesth Analg. 2009; 109(5): 1421-7. doi: 10.1213/ANE.0b013e3181b620b0. PMID: 19713260.

23) Soleimani A, Habibi MR, Hasanzadeh Kiabi F, Emami Zeydi A. Opium addiction as a novel predictor of atrial fibrillation after cardiac surgery. Int J Cardiovasc Res. 2012; 6(3): 96. PMID: 24757601, PMCID: PMC3987409.

24) Sebel PS, Bowdle TA, Ghoneim MM, Rampil IJ, Padilla RE, Gan TJ, et al. The incidence of awareness during anesthesia: a multicenter United States study. Anaesth Analg. 2004; 99(3): 833-9. doi: 10.1213/01.ANE.0000130261.90896.6C. PMID: 15333419.

25) Lopez U, Habre W, Laurençon M, Haller G, Van der Linden M, Iselin-Chaves IA. Intra-operative awareness in children: the value of an interview adapted to their cognitive abilities. Anaesthesia. 2007; 62(8): 778-89. doi: 10.1111/j.1365-2044.2007.05133.x. PMID: 17635425.

26) Ranta SO, Laurila R, Saario J, Ali-Melkkilä T, Hynynen M. Awareness with recall during general anesthesia: incidence and risk factors. Anaesth Analg. 1998; 86(5): 1084-9. doi: 10.1213/00000539199805000-00035. PMID: 9585303.

27) Osterman JE, Hopper J, Heran WJ, Keane TM, van der Kolk BA. Awareness under anesthesia and the development of posttraumatic stress disorder. Gen Hosp Psychiatry. 2001; 23(4): 198-204. doi: 10.1016/S0163-8343(01)00142-6. PMID: 11543846.

28) Kim DW, Joo JD. Comparison of the effects between mild hypothermia and normothermia on propofol or isoflurane anesthesia. 2015. Available from: http://isponline.info/2016/06/comparison-of-the-effectsbetween-mild-hypothermia-and/

29) Honan D, Doherty D, Frizelle H. A comparison of the effects on bispectral index of mild vs. moderate hypothermia during cardiopulmonary bypass. Eur J Anaesthesiol. 2006; 23(5): 385-90. doi: 10.1017/S0265021505002309. PMID: 16476186.

30) Dewandre PY, Hans P, Bonhomme V, Brichant JF, Lamy M. Effects of mild hypothermic cardiopulmonary bypass on EEG bispectral index. Acta Anaesthesiol Belg. 2000; 51(3): 187-90. PMID: 11129618.

31) Chandran Mahaldar DA, Gadhinglajkar S, Sreedhar R. Sevoflurane requirement to maintain bispectral index-guided steady-state level of anesthesia during the rewarming phase of cardiopulmonary bypass with moderate hypothermia. J Cardiothorac Vasc Anesth. 2013; 27(1): 59-62. doi: 10.1053/j.jvca.2012.05.017. PMID: 22819589.

32) Schmidlin D, Hager P, Schmid ER. Monitoring level of sedation with bispectral EEG analysis: comparison between hypothermic and normothermic cardiopulmonary bypass. Br J Anaesth. 2001; 86(6): 769-76. doi: 10.1093/bja/86.6.769. PMID: 11573582 .

33) Mathew PJ, Puri GD, Dhaliwal RS. Propofol requirement titrated to bispectral index: a comparison between hypothermic and normothermic cardiopulmonary bypass. Perfusion. 2009; 24(1): 27-32. doi: 10.1177/0267659109106071. PMID: 19567545.

34) Puri GD, Murthy SS. Bispectral index monitoring in patients undergoing cardiac surgery under cardiopulmonary bypass. Eur J Anaesthesiol. 2003; 20(6): 451-6. doi: 10.1097/00003643-20030600000004. PMID: 12803261.

35) Tirén C, Anderson RE, Barr G, Owall A, Jakobsson JG. Clinical comparison of three different anaesthetic depth monitors during cardiopulmonary bypass. Anaesthesia. 2005; 60(2): 189-93. doi: 10.1111/j.13652044.2004.04063.x. PMID: 15644019. 